\title{
Indigenous Technical Knowledge based Rainfall Prediction: A Review
}

Indigenous technical knowledge (ITK) is the actual knowledge of a given population that reflects the experiences based on tradition and includes more recent experiences with modern technologies. Traditionally, farmers have used traditional knowledge to understand weather and climate patterns in order to make decisions about crop and irrigation cycles. This knowledge has been gained through many decades of experience and has been passed on from previous generations. The present study was undertaken with the objective of collection and documenting the indigenous technical knowledge of farmers regarding rainfall prediction based on abiotic and biotic factors which is being practiced generation after generation. Here in this paper an effort has been made to collect the abiotic and biotic factors predicting rainfall, as a part of ICAR sponsored NASF ad-hoc research project entitled "Developing climate resilient adaptive strategies for empowerment of farmers" which has been implemented in University of Agricultural Sciences, Dharwad from 2019 to 2022. Various indigenous technical knowledge are collected by analyzing the journals and newsletters, deep interaction with the farmers of study area, contacting the local resource persons and documenting oral histories without scientific validation. The study found that traditional methods of rainfall forecasting can be utilized for the purpose of short-term and long-term seasonal rainfall predictions by local communities. All available abiotic and biotic indigenous rainfall forecasting techniques may serve as alternative to modern technologies.
\end{abstract}

Key words: Abiotic factors, Biotic factors, Climate patterns, Indigenous technical knowledge (ITK), Rainfall prediction.

Weather is the most important determinant of the success or failure of agricultural enterprises, with a profound influence on crop growth, development and yield (Das et al., 2010). The vulnerability caused by weather uncertainty is embodied in the Indigenous Technical Knowledge (ITK) systems of farmers. ITK is the sum total of knowledge and practices based on people's accumulated experience in dealing with problems related to various aspects of life (Wang, 1988) ITK is unique to a culture. Largely undocumented and generally passed on from generation to generation through experimental learning processes and word of mouth, ITKbased weather forecasting practiced by humans for millennia helps to reduce uncertainty in agriculture. Before the advent of modern weather forecasting methods, rural communities used ITK, mostly based on observations of atmospheric conditions, astronomic and relief features, to predict weather over short and long periods. Accuracy of predictions was dependent upon the correct interpretation of indicators, which were in turn developed through experience, skills and insights of people over generations (Anju and Bonny, 2019)

Farmers are very astute weather watchers and are quick to recognize weather that is either favorable or unfavorable to their production systems. Local forecasting combines empirical observations and spiritual insights that draw from a variety of religious traditions. It is based on many natural, cultural and social phenomena, such as presence of visible spectrum around the sun and the moon, cloud, wind direction, lightening, thunder and weather prediction through behavior of birds and other animals. Rain forecasting based
Department of Agricultural Extension Education, College of Agriculture, University of Agricultural Sciences, Dharwad-580 005, Karnataka, India.

${ }^{1}$ ICAR-Indian Grassland and Fodder Research Institute, Jhansi284 003, Uttar Pradesh, India.

Corresponding Author: S.M. Shruthi, Department of Agricultural Extension Education, College of Agriculture, University of Agricultural Sciences, Dharwad-580 005, Karnataka, India.

Email: shrumaya569@gmail.com.

How to cite this article: Bheemappa, A., Shruthi, S.M., Maheshwari, K.D. and Biradar, N. (2022). Indigenous Technical Knowledge based Rainfall Prediction: A review. Agricultural Reviews. DOI: 10.18805/ag.R-2347.

Submitted: 11-08-2021 Accepted: 03-11-2021 Online: 07-01-2022

on 'panchang' (Hindu almanac) is a common practice among farmers (Ravi Shankar et al., 2008). Predicting weather is an important cultural component for farmers, as it is common to discuss indicators on the street, markets and with family members (Praveen et al., 2018).

Agro-ecosystem environment is largely governed by interactions between abiotic (temperature, humidity, rainfall, soil factors, pollutants etc.) and biotic (crop-plants, weeds, insect-pests, pathogens, nematodes, etc.) components. The ITKs are conceptualized in terms of biotic indicators and abiotic indicators. Biotic indicators are those living beings/ biotic agents which change their behavior with any change in the surrounding environment / weather. Abiotic indicators 
Table 1: ITK based abiotic indicators of rainfall.

\begin{tabular}{lll}
\hline Description of ITK & Reported location & Source/ Reference \\
\hline $\begin{array}{l}\text { Rohini constellation ideal for onset of S-W monsoon (Long range) } \\
\text { If there is rain during Punarvashu constellation, there will definitely be }\end{array}$ & $\begin{array}{l}\text { Andhra Pradesh } \\
\text { Gain during Pushya constellation. (Trivedi, 1986; Adhvarya, 1974) }\end{array}$ & $\begin{array}{l}\text { Ravi Shankar et al. (2008) } \\
\text { Kanani and Pastakia (1999) }\end{array}$ \\
$\begin{array}{l}\text { If the rain occurs on } 2^{\text {nd }} \text { and } 5^{\text {th }} \text { day of the first fortnight of Ashadh, } \\
\text { Gujarath }\end{array}$ & Kanani and Pastakia (1999)
\end{tabular}

there will definitely be more rain in $2^{\text {nd }}$ fortnight of Ashad and $1^{\text {st }}$

fortnight of Shravan. (Trivedi, 1986; Adhvarya, 1974)

If there is rain during Adra constellations there will be rain during the

next three constellations viz., Punarvasu, Pushya and Ashlesh.

Pattern of stars and movement of stars from west to east at night under

Gujarath

Pastakia (1999)

clear skies indicates onset of rainfall in 2 - 3 days

Low temperature at night is an indication for late onset of rains and

late planting season (September-November)

Dark gigantic clouds in west (S-W monsoon) predict arival of s-w

Gujarath

Kanani and Pastakia, (1999)

Uttarakhand

Rautela and Karki (2015)

monsoon (short range)

Low clouds indicates the onset of N-E monsoon (short range)

Rainbow in the west during S-W monsoon is an indication of onset of

S-w monsoon (short range)

Thunder during nights in October/ November indicate onset of $\mathrm{N}$ - E monsoon

South Africa

Netshiukhwi et al. (2013)

Andhra Pradesh

Ravi Shankar et al. (2008)

Lightning in the east results in onset of rains after a gap of 7- 8 hours (short range)

Wind blowing from east indicates commencement of monsoon

Westerly winds of S-W monsoon indicates commencement of monsoon North Westerly wind blows expect rain in another 2 days (High reliability) Moist soil under the stones near river or hill side or under the shade of the tree during spring and summer season indicates summer rain approaching Halo around the moon is as indication of good rain to be followed (Short Range)

Andhra Pradesh Ravi Shankar et al. (2008)

1. Andhra Pradesh, 1. Ravi Shankar et al. (2008)

2. Kerala 2. Anju and Bonny (2019)

Kerala Anju and Bonny (2019)

Andhra Pradesh Ravi Shankar et al. (2008)

1. Andhra Pradesh, 1. Ravi Shankar et al. (2008)

2. Bihar, 2. Chhabra and Haris (2014)

3. Northern India $\quad 3$. Didal et al. (2017)

Andhra Pradesh Ravi Shankar et al. (2008)

Tamil Nadu Rengalakshmi Raj (2011)

Uttarakhand Rautela and Karki (2015)

1. Andhra Pradesh 1. Ravi Shankaret al.(2008)

2. Zimbabwe 2. Shoko and Shoko (2017)

3. Kerala 3. Anju and Bonny (2019)

4. Tamil Nadu 4. Rengalakshmi Raj (2011)

Moon surrounded by moisture (profuse halo) indicates good rains

South Africa

Netshiukhwi et al. (2013)

(September/November)

Size of halo of moon; smaller the halo farther is the rain and vice-versa

indicates place of rain occurring

1. Bihar

2. Tamil Nadu

1. Chhabra and Haris (2014)

Moon with normal orientation predict the rains in soon

A ring around the moon and sun caused by light shining through sheet like

Zimbabwe

2. Rengalakshmi Raj (2011)

Uttarakhand

Shoko and Shoko (2017)

high level clouds indicates rainfall within the next two to three Days

The occurrence of an eclipse enhances chances of a god rainfall season

Zimbabwe

Rautela and Karki (2015)

Pink colored sky in the evening results in short duration high

Zimbabwe

Shoko and Shoko (2017)

intensity rains (short range)

Sky with fish skin appearance bear rain (Medium range)

If the sky becomes dark near the horizon then there will be instant rain

Red sky in the morning is considered to indicate rain, while red sky in

the evening is considered to indicate that there would be no rain

Stationary clouds during transition phase from S-W to N-E monsoon

gives rise to localized rains up to few hundred square km (short range)

Overlapping clouds gives rain (short range)

Andhra Pradesh

Ravi Shankar et al. (2008)

Andhra Pradesh

Bihar

Ravi Shankaret al. (2008)

1. Uttarakhand

Ravi Shankar et al. (2008)

2. Andhra Pradesh

1. Rautela and Karki (2015),

Andhra Pradesh

2. Ravi Shankar et al. (2008)

Ravi Shankar et al. (2008)

Andhra Pradesh

Ravi Shankar et al. (2008)

Andhra Pradesh

1. Andhra Pradesh

Ravi Shankar et al. (2008)

Dark rolling clouds with cool breeze gives rain (short range)

2.South Africa

3.Uttarakhand

1. Ravi Shankar et al. (2008)

2. Netshiukhwi et al. (2013)

3.Rautela and Karki (2015)

4.Kerala

4. Anju and Bonny (2019)

Table 1: Continue... 
Table 1: Continue...

Black cloud with no stars bring rain and not the white clouds (Good reliability)

In the cyclone period if the cloud moves in a group from east to west

expect rain in next two days (Commonly used)

White feather like column (vertically standing) cloud in the sky is an

indication that the rain is about to come (CCASF, 2017)

If the colour of the clouds is similar to the colour of the wings of the Titar

bird (Partridge) i.e. grey or black-grey and strong eastern winds are also

blowing. Then assured rainfall is predicted

Presence of water vapor and warm clouds indicates the possibility of

occurrence of rain (Medium range)

When sun sets and there was appearance of the rainbow like structure in sky

(locally it is called Dharma Ketu) then it indicates rain is likely to fall in 3-4 days after

Occurrence of red dominating rainbow indicates more rains to come (June/July)

Rainbow in the east indicate absence upcoming rain/less rain

If a rainbow appears in the east in the evening or west in the morning then it is

the prediction of it will rain on that days

Thunder and lightning indicate upcoming rain

Less thunder sequence gives rain (short range)

Lightning in N-E before onset of S-W monsoon is an indication of good rains

Lighting in the east indicates onset of rain

If lightning happens in the southeast and northwest directions,

expect rain in the night (Highly used )

If there is more wind during (July - Aug) expect good rain at October - November

Roaring sea indicates occurrence of rain (short range)

High humidity and temperature indicates nearby rain (short range)

Northern winds with rain bearing clouds indicates occurrence of rain (short range)

Easterly winds during S-W monsoon indicates rain occurs

during $s-w$ monsoon (Medium range)

Cool breezes with moisture indicates occurrence of heavy rains (short range)

Wind starts blowing irregularly that has no fixed direction, nor can any fixed speed indicates rainfall be expected shortly

The dominance of a westerly wind enhance chances of a good rainfall season

Drying up of wells, springs, river and wetlands rapidly Is an indication

of good rains (Spring)

If the wind blows from the West, there will be a good monsoon; if it blows from the East, it will rain only at some places and other places will remain dry. If it blows from the South, there will be no crop production at all; if it blows from the North, there will be excessive rain.

\author{
Tamil Nadu \\ Tamil Nadu \\ Rengalakshmi Raj (2011) \\ Rengalakshmi Raj (2011) \\ Ethiopia \\ Okwibale et al. (2018)
}

Hyderabad

Didal et al. (2017)

Andhra Pradesh

Ravi Shankar et al. (2008)

Manipur

Santosh and Chhetry (2012)

South Africa

Kerala

Tamil Nadu

Kerala

Andhra Pradesh

Andhra Pradesh

Andhra Pradesh

Tamil Nadu

Tamil Nadu

Andhra Pradesh

Andhra Pradesh

Andhra Pradesh

Andhra Pradesh

1. Andhra Pradesh,

2. Kerala

Bihar

1. Zimbabwe

2. Tamil Nadu

South Africa

Gujarat

Netshiukhwi et al. (2013) Anju and Bonny (2019)

TNAU Agricultural Portal: Indigenous Farming

Anju and Bonny (2019)

Ravi Shankar et al. (2008)

Ravi Shankar et al. (2008)

Ravi Shankar et al. (2008)

Rengalakshmi Raj (2011)

Rengalakshmi Raj (2011)

Ravi Shankar et al. (2008)

Ravi Shankar et al. (2008)

Ravi Shankar et al. (2008)

Ravi Shankar et al. (2008)

1. Ravi Shankar et al. (2008)

2. Anju and Bonny (2019)

Chhabra and Haris (2014)

1.Shoko and Shoko (2017)

2.TNAU Agricultural Portal:

Indigenous Farming

Netshiukhwi et al. (2013)

Honey Bee Network are those non-living phenomena / materials that change in response to the change in the surrounding environment. By watching those behavioral changes of the nature closely, people predict the present and future events like weather (Mishra, 2020).

The vulnerability caused by vagaries of weather situation creates a knowledge base among farmers in the form of Indigenous Technical Knowledge (ITK) that helps to overcome the uncertainties and prepares for possible events (Sumit and Shivani, 2021). Local indicators and local knowledge systems cannot be replaced with scientific knowledge, because they are holistic, providing farmers with the ability to decide and prepare psychologically for the coming agricultural year (Pandey et al., 2017). Mechanisms for integrating both traditional and scientific weather forecast systems would improve understanding of uncertainties and limitations to application of farm management, as well as form a basis for fitting scientific forecasts into existing decision processes of farmers. 
Indigenous Technical Knowledge Based Rainfall Prediction: A Review

Table 2: ITK based Biotic indicators of rainfall.

Description of ITK
clouds indicates occurrence of rain.

Swallows flying at low altitude indicates rains to fall immediately.

Poultry inserting feathers in the soil indicates occurrence of rain. Domestic hens/cocks searching food during rain considered to indicate that the rain would continue.

Parabolic flight of Open bill stork (Asian bill) indicates rain.

Peacock making sound early in the morning or late in the evening indicates possible occurrence of rainfall.

Squeaking of owls is the indicator of rain

Migration of parrots in north-south direction is the indicator of rain.

Singing of black cuckoo is taken as indicator of rainfall

Positioning of the nest by weaver birds, if the nest is built near the

bottom of the well it indicates poor rainfall, if the nest is built at the top of the well indicates good monsoon.

If the maina bird bathes in the water it indicates that there will be rainfall within 1-2 days.

During the rainy season farmers observe the house swift bird and they predict heavy rainfall if the birds flies high in the sky.

Calves jumping around happily on their way to home from grazing indicates good rain on the way.

It will rain if the cattle look at the sky frequently.

Grazing cows returning home early with raised tails is considered

to indicate rain.

Croaking of frogs underneath stones and in a water body during

afternoon, leaping of small frogs indicates imminent rain.

Increased libido in sheep and goat with frequent mating is a

sign of good rain (July-August).

Flapping of ears by goats indicates short term occurrence

of rain in the rainy season.

Foxes howling in the morning and evening.

Presence of millipedes indicates onset of rainfall.

If centipedes emerge from their holes carrying their eggs in swarms

in order to shift them to safer places then farmers predicts early rainfall.

When big black scorpion appears frequently on the farm indicates

occurrence of rainfall.

Appearance of red ants and rapidly increasing size of anthills

which are moist is used to predict good rains.

Ants moving in a row, searching food indicates rainy season is approaching.

Ants sealing off holes into ant mound indicates rain to fall very soon.

Spiders leaving their webs indicates occurrence of rain.

When the rain is about to begin, the spider makes its web in opposite direction i.e., vertical to the earth and sky and after rain the direction of the web is horizontal to the earth and sky

Appearance of winged termites after a dry spell of some days indicates occurrence of rain

Termites developing living hills at corner bunds indicates good rain.

$\begin{array}{ll}\text { Reported location } & \text { Source/ Reference } \\ \text { Uttarakhand } & \text { Rautela and Karki (2015) } \\ \text { 1. Zimbabwe } & \text { 1. Shoko and Shoko (2017) } \\ \text { 2. Uttarakhand } & \text { 2. Rautela and Karki (2015) } \\ \text { Andhra Pradesh } & \begin{array}{l}\text { Ravi Shankar et al. (2008), } \\ \text { Uttarakhand }\end{array} \\ \end{array}$

Zimbabwe

Shoko and Shoko (2017)

Andhra Pradesh

Ravi Shankar et al. (2008),

Andhra Pradesh

Ravi Shankar et al. (2008)

Andhra Pradesh

Andhra Pradesh

Ravi Shankar et al. (2008)

Ravi Shankar et al. (2008)

Andhra Pradesh

Ravi Shankar et al. (2008)

1. Tamil Nadu

1. Ravi Shankar et al. (2008)

2. Andhra Pradesh

Andhra Pradesh

2. Rengalakshmi Raj (2011)

Ravi Shankar et al. (2008)

Andhra Pradesh

Ravi Shankar et al. (2008)

Tamil Nadu

Andhra Pradesh

Rengalakshmi Raj (2011)

Ravi Shankar et al. (2008)

Andhra Pradesh

Ravi Shankar et al. (2008)

Andhra Pradesh

Ravi Shankar et al. (2008)

Andhra Pradesh

Ravi Shankar et al. (2008)

Uttarakhand

Rautela and Karki (2015)

Zimbabwe

Shoko and Shoko (2017)

Tamil Nadu

Rengalakshmi Raj (2011)

Andhra Pradesh Ravi Shankar et al. (2008)

Andhra Pradesh Ravi Shankar et al. (2008)

1. Zimbabwe

2. Tamil Nadu

Zimbabwe

Uttarakhand

Nepal

1. Shoko and Shoko (2017)

2. Rengalakshmi Raj (2011)

Shoko and Shoko (2017)

Rautela and Karki (2015)

Frand et al. (2012)

Andhra Pradesh Ravi Shankar et al. (2008)

1.Tamil Nadu 1.Rengalakshmi Raj (2011)

2.Andhra Pradesh 2.Ravi Shankar et al. (2008) 
Table 2: Continue...

Movement of dragon flies indicates occurrence of rain

Movement of red hairy caterpillar, as the humidity increases beyond

90 per cent their quick movement is considered as an indicator of rain.

If grass hopper is in a group of 10-12 then, it is supposed that rain

will occur in next 24 hours

Flight of butterflies from north -south direction the arrival of rainfall.

If the leeches are moving rapidly in the upward and downward

direction in water then rainfall is predicted.

Large number of fireflies seen at night on the forest trees is a sign

that the monsoon will start early.

If the field cricket brings new soil particles out of its holes during the dry season, it is thought that rain is coming soon. if the same activity occurs

during the rainy season a heavy rain is expected during the rainy season.

Snakes moving down the mountain sign of good rain.

Frequent appearance of tortoise, wondering around indicates that we get good rain.

Full bloom of neem tree in summer indicates onset of monsoon triggering heavy rains.

As soon as the neem kernels ripen and start falling, it is expected that

there will be rain after 10-15 days.

Neem flower blooms 40 days before monsoon sets in.

When honey tree starts flowering, early onset of rainy season is expected.

Abundance of mushroom both edible and wild indicates good

rainfall distribution for the year.

The rain will appear after 10-15 days of flowering in babul tree (Acacia nilotica).

In castor (Ricinous spp) and ber (Ziziphus nummularia) when buds

start sprouting, then it is predicted that rain will appear within 10-15 days.

When the adventitious roots of banyan tree (Ficus bengalensis) start sprouting

(tillering) and then the local people assumes that the rain will appear with in 2-4 days.

$\begin{array}{ll}\begin{array}{l}\text { Andhra Pradesh } \\ \text { Nepal }\end{array} & \begin{array}{l}\text { Ravi Shankar et al. (2008) } \\ \text { Frand et al. (2012) }\end{array} \\ \text { Nepal } & \text { Frand et al. (2012) }\end{array}$

Tamil Nadu

Tamil Nadu

Rengalakshmi Raj (2011)

Rengalakshmi Raj (2011)

Maharashtra

Didal et.al. (2017)

Mizoram

Chinlampianga (2011)

Uttarakhand

Uttarakhand

Andhra Pradesh

Tamil Nadu

Andhra Pradesh

Uttarakhand

Uttarakhand

Tamil Nadu

Tamil Nadu

Tamil Nadu

Rautela and Karki (2015)

Rautela and Karki (2015)

Ravi Shankar et al. (2008)

Rengalakshmi Raj (2011)

Ravi Shankar et al. (2008)

Rautela and Karki (2015)

Rautela and Karki (2015)

Rengalakshmi Raj (2011)

Rengalakshmi Raj (2011)

Rengalakshmi Raj (2011)
ITKs related to rainfall prediction were collected and documented by analyzing the journals and newspapers and interaction with some of the farmers in Gadag, Belgaum and Uttara Kannada district as a part of ICAR sponsored NASF ad-hoc research project entitled "Developing Climate Resilient Adaptive Strategies for Empowerment of Farmers" which has been implemented in University of Agricultural Sciences, Dharwad from 2019 to 2022.

There is no fixed method of collection of ITKs. It depends on type of ITK, situation, people, social system, cultural values and other aspects (Pandey et al., 2017). The study is solely based on secondary data collected by studying and analyzing the journals, textbooks and E-newsletter.

\section{Type of documentation}

Documenting the large variety of indigenous technical knowledge based practices without scientific validation and documenting the prevalent practices with the traditional one (Prakash et al., 2012).

A look into the tables provides us some identified ITKs and their location of use by people.

\section{CONCLUSION}

Rainfall prediction/ forecast is defined as to tell before hand when, where and how it would rain. Unfortunately, even though advanced technology, including the use of satellites and statistical monsoon prediction models exists, a great deal of credibility is still placed by some indivividuals on astrology even today for thousands of years, India has been using astrology, study of clouds, direction of winds, position of the sun and the moon and observation of bioindicators like plants, animals, birds, insects etc., for forecasting of rain (Sivaprakasam and Kanakasabai, 2009).

Farming communities are generally aware of the ITKs of rainfall prediction in their own region the knowledge on rainfall prediction held by local community can play significant role in developing location specific package of practices for specially agriculture (Chinlampianga, 2011). The traditional methods of rainfall forecasting may be riddle with inaccuracies but the cannot be ignored altogether. The traditional wisdom may be explored with scientific knowledge to come out with an error free system of forecasting, which is very crucial for a predominantly agricultural country like India that depends so much on the rains (Sivaprakasam and Kanakasabai, 2009).

\section{ACKNOWLEDGEMENT}

The study is a part of ICAR- NASF through ad hoc project on "Developing Climate Resilient Adaptive Strategies for 
Empowerment of Farmers (2019-22)". We wish to thank the authors of the referred research papers for publishing their works in different journals, books and E-newsletter.

\section{REFERENCES}

Anju, R. and Bonny, B.P. (2019) Indigenous knowledge based abiotic indicators used in weather prediction by farmers of Wayanad, Kerala, India. Indian Journal of Traditional Knowledge. 18(3): 565-572.

Chhabra, V. and Haris, A.A. (2014), Nakshtra based rainfall analysis and its impact on rabi crops yield for Patna, Bihar. Sch. J. Agric. Vet. Sci. 1(4): 168-172.

Chinlampianga, M. (2011), Traditional knowledge, weather prediction and bioindicators: A case study in Mizoram, north eastern India. Indian Journal of Traditional Knowledge. 10(11): 207-211.

Das, H.P., Doblas, R.F.J., Garcia, A., Hansen, J., Mariani, L., Nain, A., Ramesh, K., Rathore, L.S. and Venkataraman, R. Weather and climate forecasts for agriculture. Guide to Agricultural Meteorological Practices (GAMP), (WMO, Geneva, Switzerland) 2010. 103.

Didal, V.K., Brijbhooshan, Todawat, A. and Choudhary, K., 2017. Weather forecasting in India: A Review, Int. J. Curr. Microbiol. App. Sci. 6(11): 577-590.

Fand, B.B., Kamble, A.L. and Kumar, M. (2012) Will climate change pose serious threat to crop pest management: A critical review. International Journal of Scientific and Research Publications. 2(11): 1-14. Honey bee Network, https://www.honeybee.org/.

Mishra, A., Singh, S.R.K., Raut, A.A. 2020, Traditional knowledge in agriculture, Division of Agricultural Extension, ICAR, New Delhi. 1-52.

Netshiukhwi, G.Z., Stigter, K. and Walker, S. (2013), Use of traditional weather/climate knowledge by farmers in the southwestern free state of South Africa: Agro Meteorological Learning by Scientists. 4: 383-410.

Okwibale, P.M., Ansah, P., Boroto, R.J., Nkegbe, A., Deridder, B.S. et al., (2018). Compendium of community and indigenous strategies for climate change adaptation with focus on addressing water scarcity in agriculture. Report submitted to FAO: 1-113.
Prakash, N., Roy, S.S. and Ngachan, S.V. (2012). http:/WWW. kiran. nic.in/pdf/publications/ITK.

Praveen, N., Sreenivasa, R. and Sudha, R.V. (2018). Rationality and validity of ITKS on general agriculture by tribal farmers in Telangana region. Int. J. Curr. Microbiol. App. Sci. 7(11): 34-39.

Rautela and Karki (2015). Weather forecasting: traditional knowledge of the people of Uttarakhand Himalaya. Journal of Geography, Environment and Earth Science International. 3(3): 1-14.

Ravi Shankar, K. Maraty, P., Murthy, V.R.K. and Ramakrishna, Y.S. (2008). Indigenous Rain Forecasting in Andhra Pradesh. Director, Central Research Institute for Dryland Agriculture, Santoshnagar, Saidabad P.O., Hyderabad.59: 1-75.

Rengalakshmi Raj (2011). Linking traditional and scientific knowledge systems on climate prediction and utilization. M.S. Swaminathan Research Foundation Chennai, India. 1-11.

Santosh, T.H. and Chhetry, G.K.N. (2012). Agro-biodiversity management related ITKs in North-Eastern India. Journal of Biology, Agriculture and Healthcare. 2(6): 83-93.

Shoko and Shoko (2017). Indigenous weather forecasting systems: a case study of the abiotic weather forecasting indicators for wards 12 and 13 in Mberengwa district Zimbabwe. Asian Social Science. 9(5): 285-297.

Sivaprakasam, S. and Kanakasabai, V. 2009, Traditional almanac predicted rainfall- A case study. Indian Journal of Technical Knowledge. 8(4): 621-625.

Sumit Sow and Shivani Ranjan, 2021, Indigenous Technical knowledge for sustainable agriculture in India. Agriculture and Food: E-Newsletter. 3(1): 30-36.

Pandey, V., Mittal, R. and Sharma, P. (2017). Documentation and application of indigenous technical knowledge for sustainable agricultural development. Asian J. of Agricultural Extension, Economics and Sociology. 15(3): 1-9.

Wang, G. (1988). Indigenous communication systems in research and development. J. Ext Sys: 75-86. 